\title{
Predictors of survival in patients with brain metastases from gastric cancer
}

\author{
D. RADES ${ }^{1, *}$, T. BARTSCHT ${ }^{2}$, S. E. SCHILD ${ }^{3}$ \\ ${ }^{1}$ Department of Radiation Oncology, University of Lübeck, Lübeck, Germany; ${ }^{2}$ Department of Hematology and Medical Oncology, University of \\ Lübeck, Lübeck, Germany; ${ }^{3}$ Department of Radiation Oncology, Mayo Clinic, Scottsdale, Arizona, USA
}

${ }^{\star}$ Correspondence: rades.dirk@gmx.net

Received June 29, 2016 / Accepted September 12, 2016

\begin{abstract}
This study aims to identify predictors of survival and contribute to treatment personalization in patients with brain metastases from gastric cancer. Twelve patients received whole-brain radiotherapy (WBRT), four stereotactic radiosurgery and six neurosurgery plus WBRT. Treatment regimen, age, gender, Eastern Cooperative Oncology Group (ECOG) performance score, tumor site, number of brain metastases, extra-cranial metastases and interval between cancer diagnosis and brain metastases were evaluated for survival. On univariate analyses, more intensive treatment ( $\mathrm{p}=0.003), \mathrm{ECOG}-\mathrm{score}$ $0-1(\mathrm{p}<0.001)$, cardiac location $(\mathrm{p}=0.025)$ and single brain metastasis $(\mathrm{p}=0.023)$ were associated with better survival. On multivariate analysis, ECOG-score maintained significance $(\mathrm{p}<0.001)$. Patients with all three positive factors on univariate analysis had a 12 -month survival rate of $100 \%$, patients with three negative factors a 3 -month survival rate of $0 \%$. Predictors of survival were identified that can guide physicians selecting personalized treatment approaches for patients with brain metastases from gastric cancer.
\end{abstract}

Key words: gastric cancer, cardiac cancer, brain metastases, radiotherapy, survival

Depending on the type of primary tumor, brain metastases occur in up to $30-40 \%$ of adult cancer patients during the disease process [1-3]. Of patients presenting with brain metastases, those with gastric cancer are very rare and account for less than $1 \%$. Therefore, little is known about this particular patient group. For patients with brain metastases, several treatments are available. The vast majority of these patients, in particular those with multiple cerebral lesions, are treated with whole-brain radiotherapy (WBRT) alone [2]. In patients with a single lesion or very few lesions, local treatments such as stereotactic radiosurgery (SRS) or neurosurgical resection, either alone or combined with WBRT, may be a reasonable option [3]. The decision process of choosing the best treatment option for an individual patient should take into account several aspects including the patient's preference, social situation and survival prognosis. Patients with poor prognoses should receive a short less burdensome treatment [4]. Symptom control and quality of life have priority. Due to the short remaining lifetime, long-term local (intracerebral) control and late toxicity are less important. In contrast, for patients with favorable survival prognoses, local control and late toxicity are more important and are critical when selecting the treatment [5]. Thus, it is desirable to be able to estimate a patient's survival prognosis before starting the treatment. This estimation can be facilitated if predictors of survival are available. Prognostic factors and scores have been identified for patients with brain metastases, mostly obtained from patients with brain metastases from different primaries [6-8]. However, it is generally agreed that identification of prognostic factors should ideally be performed in a patient cohort with brain metastases from one tumor entity to allow optimal treatment personalization [8]. This study focuses particularly on brain metastases from gastric cancer. It aims to identify predictors of survival and improve personalized care for these patients.

\section{Patients and methods}

Data from 22 patients receiving radiotherapy for brain metastases from gastric adenocarcinoma were retrospectively investigated. Twelve patients were treated with whole-brain radiotherapy (WBRT) alone (nine patients with 10x3 Gy, 
three patients with $5 \times 4 \mathrm{~Gy}$ ), four patients with stereotactic radiosurgery (SRS) alone, and six patients with neurosurgical resection followed by WBRT. The treatment regimen plus seven factors were evaluated for potential associations with survival. Additional factors were age ( $\leq 65$ vs. $\geq 66$ years; median age: 65.5 years), gender, Eastern Cooperative Oncology Group (ECOG) performance score (0-1 vs. 2-3), tumor site (cardiac vs. other gastric sites), number of brain metastases ( 1 vs. $\geq 2$; median number: 1 ), extra-cranial metastases (no vs. yes), and the interval between cancer diagnosis and detection of brain metastases ( $\leq 10$ vs. $>10$ months; median interval: 10 months). Univariate analyses of the eight factors were performed with Kaplan-Meier method and log-rank test. Factors achieving significance on univariate analyses $(\mathrm{p}<0.05)$ or showed a trend $(\mathrm{p}<0.055)$ were included in a multivariate analysis (Cox regression model).

\section{Results}

On univariate analyses, treatment regimen (WBRT vs SRS alone or surgery followed by WBRT, $\mathrm{p}=0.003$ ), ECOG performance score of $0-1(\mathrm{p}<0.001)$, cardiac location $(\mathrm{p}=0.025)$ and single brain metastasis $(\mathrm{p}=0.023)$ were significantly associated with better survival, and absence of

Table 1. Survival rates at 6 and 12 months following radiotherapy.

\begin{tabular}{|c|c|c|c|}
\hline & $\begin{array}{l}\text { At } 6 \text { months } \\
(\%)\end{array}$ & $\begin{array}{l}\text { At } 12 \text { months } \\
(\%)\end{array}$ & $\mathbf{P}$ \\
\hline \multicolumn{4}{|l|}{ Treatment regimen } \\
\hline WBRT alone $(\mathrm{n}=12)$ & 8 & 0 & \\
\hline SRS alone $(n=4)$ & 75 & 50 & \\
\hline Surgery + WBRT $(\mathrm{n}=6)$ & 67 & 44 & 0.003 \\
\hline \multicolumn{4}{|l|}{ Age } \\
\hline$\leq 65$ years $(n=11)$ & 27 & 14 & \\
\hline$\geq 66$ years $(n=11)$ & 45 & 36 & 0.37 \\
\hline \multicolumn{4}{|l|}{ Gender } \\
\hline female $(n=3)$ & 67 & 33 & \\
\hline male $(n=19)$ & 32 & 25 & 0.96 \\
\hline \multicolumn{4}{|l|}{ ECOG performance score } \\
\hline $0-1(\mathrm{n}=8)$ & 100 & 71 & \\
\hline $2-3(n=14)$ & 0 & 0 & $<0.001$ \\
\hline \multicolumn{4}{|l|}{ Tumor site } \\
\hline Non-cardiac gastric cancer $(n=13)$ & 23 & 8 & \\
\hline Cardiac cancer $(\mathrm{n}=9)$ & 56 & 56 & 0.025 \\
\hline \multicolumn{4}{|l|}{ Number of brain metatsases } \\
\hline $1(\mathrm{n}=14)$ & 50 & 33 & \\
\hline$\geq 2(\mathrm{n}=8)$ & 13 & 0 & 0.023 \\
\hline \multicolumn{4}{|l|}{ Extra-cranial metastases } \\
\hline No $(n=9)$ & 56 & 28 & \\
\hline Yes $(n=13)$ & 23 & 23 & 0.051 \\
\hline \multicolumn{4}{|l|}{$\begin{array}{l}\text { Interval from cancer diagnosis to } \\
\text { detection of brain metastases }\end{array}$} \\
\hline$\leq 10$ months $(\mathrm{n}=12)$ & 17 & 17 & \\
\hline$>10$ months $(\mathrm{n}=10)$ & 60 & 36 & 0.11 \\
\hline
\end{tabular}

$\mathrm{WBRT}=$ whole-brain radiotherapy, $\mathrm{SRS}=$ stereotactcic radiosurgery, ECOG=Eastern Cooperative Oncology Group extracranial metastases $(\mathrm{p}=0.051)$ showed a trend (Table 1$)$. On subsequent multivariate analyses, the ECOG performance score maintained significance $(\mathrm{p}<0.001)$, whereas treatment regimen $(\mathrm{p}=0.44)$, tumor site $\mathrm{p}=0.43)$, number of brain metastases $(\mathrm{p}=0.75)$ and extracranial metastases $(\mathrm{p}=0.29)$ were not significant. Results of the multivariate analysis including risk ratios and $95 \%$-confidence intervals are given in Table 2.

The four patients who had all three positive prognostic factors according to the univariate analysis, i.e. an ECOG performance score of $0-1$, cardiac location and a single brain metastasis, achieved a survival rate of $100 \%$ at both 6 months and 12 months. In contrast, the six patients who had all three negative factors, i.e. an ECOG performance score of 2-3, gastric cancer and $\geq 2$ brain metastases had a 3-month survival rate of $0 \%$ and a median survival time of only 1 month.

\section{Discussion}

Personalization of cancer treatment has gained importance during recent years, in particular for cancer patients with metastatic disease. In case of brain metastases, many patients have a very limited survival prognosis of only very few months. However, an increasing proportion of patients with brain metastases live longer, some for years. Depending on the remaining lifetime, patients require different therapeutic strategies. Patients with very poor prognosis should receive a less encumbering program with a short overall treatment time, namely WBRT with 5x4 Gy in 1 week [4]. In contrast, patients with relatively good prognoses could benefit from longer-course WBRT (for example 20x2 Gy in 4 weeks) or more intensive local treatments such as SRS and resection. This applies also to patients with brain metastases from gastric cancer. Many patients with advanced gastric cancer, in particular those with metastatic disease have a poor prognosis, which strongly needs to be improved [9-12]. This can possibly be achieved with optimal personalization of the corresponding treatment approaches.

Table 2. Multivariate analysis of survival.

\begin{tabular}{lccc}
\hline & $\begin{array}{c}\text { Risk } \\
\text { ratio }\end{array}$ & $\begin{array}{c}\text { 95\%-confi- } \\
\text { dence interval }\end{array}$ & P \\
\hline $\begin{array}{l}\text { Treatment regimen } \\
\text { WBRT vs. SRS vs. Surgery + WBRT }\end{array}$ & 0.87 & $0.59-1.25$ & 0.44 \\
$\begin{array}{l}\text { ECOG performance score } \\
\quad 0-1 \text { vs. 2-3 }\end{array}$ & $4.65 \mathrm{e}+9$ & $0-\mathrm{n} / \mathrm{a}$ & $<\mathbf{0 . 0 0 1}$ \\
$\begin{array}{l}\text { Tumor site } \\
\quad \text { Non-cardia cancer vs. cardia cancer }\end{array}$ & 0.62 & $0.16-1.98$ & 0.43 \\
$\begin{array}{l}\text { Number of brain metatsases } \\
\quad \text { vs. } \geq 2\end{array}$ & 1.23 & $0.35-4.80$ & 0.75 \\
$\begin{array}{l}\text { Extra-cranial metastases } \\
\quad \text { No vs. Yes }\end{array}$ & 2.07 & $0.53-8.61$ & 0.29 \\
\hline $\begin{array}{l}\text { WBRT=whole-brain radiotherapy, SRS=stereotactcic radiosurgery, } \\
\text { ECOG=Eastern Cooperative Oncology Group, n/a=not available }\end{array}$ & & & \\
$\quad$
\end{tabular}


In order to select the optimal program for an individual patient with brain metastases from gastric cancer, it appears mandatory to know the remaining lifetime as precisely as possible. The current study was initiated to identify factors that help predict an individual patient's survival prognosis. In this study, the ECOG performance score proved to be an independent predictor of survival. This finding agrees with previous studies performed in cohorts of patients with brain metastases from different primary tumors $[6,7]$. Furthermore, in a subgroup analysis of another retrospective study focusing on patients with brain metastases from gastrointestinal cancers without further specification, the performance status was the only factor that was significantly associated with survival [8].

In the present study, in addition to the ECOG performance score, tumor site and number of brain metastases were significantly associated with survival on univariate analysis. In patients who had an ECOG performance score of $0-1$, cardia cancer and only a single brain metastasis, the 12 -month survival rate was $100 \%$. These patients might benefit from longer-course WBRT with 20x2 Gy. A previous retrospective study of 184 patients with brain metastases and a favorable survival prognosis, WBRT with $20 \times 2$ Gy in 4 weeks resulted in significantly better 1 -year local control ( $44 \%$ vs. $28 \%, \mathrm{p}=0.047$ on multivariate analysis) and 1 -year survival ( $61 \%$ vs. $50 \%, p=0.008$ on multivariate analysis) than 10x3 Gy in 2 weeks [5]. In case of very few brain metastases (1 to 3-4), local therapies such as SRS and neurosurgical resection, either alone or supplemented by WBRT are reasonable options, since these programs result in better local control and survival than WBRT alone in these patients $[3,13]$.

In this study, patients with an ECOG performance score of 2-3, non-cardiac primaries and $\geq 2$ brain metastases had a median survival or only one month. These patients should receive best supportive care alone or supplemented with $5 \times 4$ Gy of WBRT in 1 week. A previous study suggested that WBRT with $5 \times 4$ Gy is similarly effective as $10 \times 3$ Gy in terms of intracerebral control and survival in patients with multiple brain metastases [4]. However, best supportive care alone may also be an appropriate option for these patients as recently demonstrated in a randomized trial of patients with brain metastases from non-small cell lung cancer [14]. When interpreting this study, the retrospective nature and small number of patients should be considered. The results of this study should ideally be confirmed in a larger prospective series of patients. However, because patients with brain metastases from gastric cancer are very rare, such a study cannot be expected soon.

In conclusion, this study identified predictors of survival and both patients with a very poor and those with a favorable survival prognosis. Since a personalized treatment approach must consider a patient's remaining survival time, this study can guide physicians when selecting the treatment for patients with brain metastases from gastric cancer.

\section{References}

[1] WEN PY, BLACK PM, LOEFFLER JS. Metastatic brain cancer. In DeVita V, Hellman S, and Rosenberg SA; editors Cancer: principles and practice of oncology. 6th Edition. Philadelphia: Lippincott, Williams \& Wilkins, 2001: 2655-2670.

[2] KHUNTIA D, BROWN P, LI J, MEHTA MP. Whole-brain radiotherapy in the management of brain metastasis. J Clin Oncol 2006; 24: 1295-1304. https:/doi.org/10.1200/ JCO.2005.04.6185

[3] TSAO MN, RADES D, WIRTH A, LO SS, DANIELSON $\mathrm{BL}$ et al. Radiotherapeutic and surgical management for newly diagnosed brain metastasis(es): An American Society for Radiation Oncology evidence-based guideline. Pract Radiat Oncol 2012; 2: 210-225. https:/doi.org/10.1016/j. prro.2011.12.004

[4] RADES D, KIECKEBUSCH S, LOHYNSKA R, VENINGA T, STALPERS LJ et al. Reduction of overall treatment time in patients irradiated for more than three brain metastases. Int J Radiat Oncol Biol Phys 2007; 69: 1509-1513. https:/doi. org/10.1016/j.ijrobp.2007.05.014

[5] RADES D, PANZNER A, DZIGGEL L, HAATANEN T, LOHYNSKA R et al. Dose-escalation of whole-brain radiotherapy for brain metastasis in patients with a favorable survival prognosis. Cancer 2012; 118: 3853-3859. https:/doi.org/10.1002/ cncr.26680

[6] GASPAR L, SCOTT C, ROTMAN M, ASBELL S, PHILLIPS $\mathrm{T}$ et al. Recursive partitioning analysis (RPA) of prognostic factors in three Radiation Therapy Oncology Group (RTOG) brain metastases trials. Int J Radiat Oncol Biol Phys 1997; 37: 745-751. https:/doi.org/10.1016/S03603016(96)00619-0

[7] DZIGGEL L, SEGEDIN B, PODVRSNIK NH, OBLAK I, SCHILD SE et al. Validation of a survival score for patients treated with whole-brain radiotherapy for brain metastases. Strahlenther Onkol 2013; 189: 364-366. https:/doi. org/10.1007/s00066-013-0308-3

[8] SPERDUTO PW, CHAO ST, SNEED PK, LUO X, SUH J et al. Diagnosis-specific prognostic factors, indexes, and treatment outcomes for patients with newly diagnosed brain metastases: A multi-institutional analysis of 4,259 patients. Int J Radiat Oncol Biol Phys 2010; 77: 655-661. https:/doi.org/10.1016/j. ijrobp.2009.08.025

[9] DANG SC, FENG S, WANG PJ, CUI L, QU JG et al. Overexpression of Survivin mutant Thr34Ala induces apoptosis and inhibits gastric cancer growth. Neoplasma 2015; 62: 81-87. https:/doi.org/10.4149/neo 2015010

[10] LI X, LIU H, YI T, DONG Z, TANG L et al. Loss of MTUS1 in gastric cancer promotes tumor growth and metastasis. Neoplasma 2014; 61: 128-135. https:/doi.org/10.4149/ neo 2014018

[11] SLAVIK M, BURKON P, KAZDA T, BUDIKOVA M, SLAVIKOVA $M$ et al. Toxicity and survival outcomes of adjuvant chemoradiation for gastric and gastroesophageal junction cancer patients treated in period 2006-2009: an institutional experience. Neoplasma 2014; 61: 739-746. https:/doi. org/10.4149/neo 2014090 
[12] SHENG H, SHEN W, ZENG J, XI L, DENG L. Prognostic significance of TMPRSS4 in gastric cancer. Neoplasma 2014; 61: 213-217. https:/doi.org/10.4149/neo 2014027

[13] RADES D, PLUEMER A, VENINGA T, HANSSENS P, DUNST J et al. Whole-brain radiotherapy versus stereotactic radiosurgery for patients in recursive partitioning analysis classes 1 and 2 with 1 to 3 brain metastases. Cancer 2007; 110: 2285-2292. https:/doi.org/10.1002/cncr.23037
[14] MULVENNA PM, NANKIVELL MG, BARTON R, FAIVREFINN C, WILSON P et al. Whole brain radiotherapy for brain metastases from non-small lung cancer: Quality of life (QoL) and overall survival (OS) results from the UK Medical Research Council QUARTZ randomised clinical trial (ISRCTN 3826061). J Clin Oncol 2015; 33 (suppl): abstr 8005. 